\title{
Managing asymmetric conflict
}

\author{
J Paul Dunne, \\ University of the West of England \\ María D. C. García-Alonso, \\ University of Kent \\ Paul Levine, \\ Ron P Smith, \\ University of Surrey \\ Birkbeck College
}

September 26, 2005

\begin{abstract}
This paper considers a simple model of asymmetric conflict, between an incumbent, e.g. government or dominant firm, and potential challengers, e.g. guerrillas or entrants. It is not uncommon for challengers to win such conflicts despite their lack of resources. One way they can do this by exploiting a second mover advantage: choosing to attack the incumbent in ways that it had not prepared for, because it was locked in by past investments. To model such asymmetric conflict we use a three stage game. In the first stage the incumbent chooses effort; in the second stage the challengers choose the degree of differentiation from the incumbent and in the third stage each decide whether to attack or defend and collect their payoffs. Although the game is simple, the calculations required from the players are difficult and shed light on the complexities of many conflicts.
\end{abstract}

JEL codes: L10, D74.

Corresponding author: María García-Alonso, Department of Economics, University of Kent at Canterbury, Canterbury, Kent, CT2 7NZ. 


\section{Introduction}

Conflict is endemic in social and economic interaction. In addition to the obvious case of military combat, legal disputes, and commercial battles to establish market share or standards all involve conflicts between agents and all have been the focus of economic analysis. Economic models of conflict, generally treat agents as allocating resources (e.g. military expenditures, legal fees, advertising or $\mathrm{R} \& \mathrm{D}$ budgets) to conflict as well as to productive activities, e.g. Hirschleifer (2001), Grossman (1991), and Grossman and Kim (1995). The relative investments of the antagonists then determines their probability of winning through a 'conflict success function', CSF. Like Voltaire, most CSFs assume that God is on the side of the big battalions, in the sense that those who invest most are likely to win. However, in real life, like Hollywood movies, the little guys win more often than one might expect, for example Japan beating Russia in 1905-6, Germany beating larger French and British forces in 1940 and Vietnam beating the US in the 1970s. Indeed, using a large sample of battles, Rotte and Schmidt (2003) show that relative force size is a poor predictor of victory. Instead, much quantitative analysis suggests that the strategy adopted is the most important determinant of victory in war, Reiter (1999). On the basis of a quantitative analysis Arreguin-Toft (2001) concludes that 'strong actors lose asymmetric conflicts when they adopt the wrong strategy vis-a-vis their weaker adversaries.'

It is often the case that a dominant incumbent is beaten by smaller challengers, because the challengers fight in ways the incumbent was unprepared for, being locked in to a particular way of fighting. Currently, the military call this asymmetric warfare, though attacking in ways that your opponent was unprepared for has in fact been standard in military thought since at least Sun Tzu in the fourth century BC (Newman, 2000). The current US concern arises because its focus on standard warfare, in which it is dominant, tends to give its adversaries an incentive to differentiate, in the sense of adopting idiosyncratic technologies or tactics. Again there are historical precedents. Clearly, the US were differentiated from their Vietnamese opponents in level of resources available, level of military technology, type of warfare (conventional or guerrilla), and in perceived costs of conflict (the Vietnamese were willing to take much larger casualties than the US). Also, as Enders and Sandler (1993, 2004) and Sandler and Arce (2003) note, when terrorists have a choice of targets (e.g. different countries or different objectives within the same 
country) effort being put into defending one target will provide incentives for the terrorists to differentiate, to substitute alternative targets. For example, in response to British counter-terrorism efforts, the IRA switched from attacking military targets in Northern Ireland, firstly to civilian targets in Britain, and then to high value commercial targets in the City of London.

There are also many commercial examples of powerful incumbents being displaced by small challengers. The large US automobile companies lost their dominant market share to small importers against whom they could not compete, Abernathy (1978) provides a classic analysis of the lock-in dilemma they faced, leaving their challengers a second-mover advantage. IBM was the dominant player in the computing industry, with a particular way of doing business and a well established customer base ${ }^{1}$, but small challengers, Intel and Microsoft, displaced IBM as monopolists (Bresnahan and Greenstein, 1999; Sutton, 2001). Microsoft's tactics for displacing software incumbents are discussed in Liebowitz and Margolis (1999). Now, Microsoft and Intel are the incumbents, currently vulnerable to small challengers, such as Open Source Linux and different types of processors. Non-economists have an obvious explanation of such phenomena: the ignorance and incompetence of the incumbents and there is a large literature on military incompetence and how the ignorance and megalomania of chief executives destroys their firms. Economists, while averse to explanations based on ignorance and incompetence, tend to lack alternatives.

This paper presents a simple model that captures how in response to incumbent investment, challengers differentiate in order to reduce the value of that investment, thus giving the challengers a chance of winning; even when the powerful incumbent is neither ignorant nor incompetent. There is a prize, peace in Iraq or market dominance, which can be achieved by a three stage game. In Stage 1, the incumbent decides how much effort to invest to counter the threat and becomes locked into that investment. In Stage 2, the challengers, who are resource constrained and whose effort is given, decide how much to differentiate from the incumbent. Finally, in stage 3, incumbent and challengers simultaneously decide whether to attack or defend. The probabilities of winning depend on the attack/defend decisions of the two parties, their efforts and the degree of differentiation. Differentiation benefits an attacker but disadvantages a defender, thus acts like a commit-

\footnotetext{
${ }^{1}$ A related reason for lock-in, discussed in Chen (2000), is the fear that innovation may cannibalise existing businesses, which was important in the case of IBM.
} 
ment technology to the challengers. There are costs of conflict, since if either attack some of the contested resources are destroyed in the resulting conflict, and these costs differ by agent and type of conflict; e.g. destruction being higher in a situation of mutual attack.

There are four possible outcomes. First, there is (hostile) peace, if both sides decide to defend. Second, there is unprovoked attack if the incumbent attacks peaceful challengers. We rule out this outcome by assuming that a characteristic of a dominant incumbent is that they are satisfied with the status quo. Third, there is defensive conflict if the incumbent defends against challengers attack. Fourth, there is mutual attack, if both incumbent and challengers attack.

Although the game is simple, the calculations required from the players are difficult and shed some light on the complexities of real conflicts. Being able to differentiate increases the incentive for the challengers to attack, making the world more dangerous for the incumbent and requiring it to expend more effort to deter attack and maintain peace. In fact, there may be no level of incumbent effort which can maintain peace. Even if there is a level of effort that could deter attack, it may be cheaper for the incumbent to defend against an attack than to deter it $^{2}$. In this case, defensive conflict, differentiation reduces the effectiveness and the level of incumbent effort: military expenditure buys less security and so less is purchased.

Section 2 describes the basic model. Section 3 finds the solution to the game. Section 4 introduces a fixed cost of differentiation Section 5 has some concluding comments.

\section{The model}

\subsection{Structure of the game}

Consider two parties, incumbent $a$, and challengers $b$, who are rational players of a sequential three stage game to gain a prize of value $V$. Part of the prize may be simply surviving and the costs of conflict, introduced below, may include lives lost. We assume that both parties are materially rather than ideologically motivated and so they fight be-

\footnotetext{
${ }^{2}$ For a monopolist the size of the sunk costs necessary to deter entrants may be very large relative to the cost of defending their market against them. In some cases it may be worth incurring vast sunk costs, e.g. the massive Cold War arsenals, because the costs of conflict are larger. Intriligator (1975) provides a model.
} 
cause the expected value of fighting is greater than the expected value of peace. Collier and Hoeffler (1998) provide evidence that this describes most civil wars. The three stage game determines the incumbent's effort, the challengers' differentiation, the nature of the conflict, and the payoffs.

Stage 1: Incumbent chooses effort, $e_{a}$ with $\operatorname{cost} C_{a}\left(e_{a}\right)$. Cost increases with effort and the second derivative is such that the expected utility function is concave. The challengers effort $e_{b}$ is considered fixed.

Stage 2: Challengers choose a degree of differentiation from the incumbent, $t$. The incumbent's choice is determined by prior investments.

Stage 3: Incumbent and challengers simultaneously decide whether to attack or defend and get their payoffs. Since there is no way either of the parties can credibly commit to attack or defend before the other, we assume, like much of the industrial organisation literature, that the decision is simultaneous.

The game is solved backwards to find the Subgame Perfect Equilibrium for incumbent effort and challengers differentiation, which will result in a unique pure strategy equilibrium in the third stage of the game.

This structure captures two sources of asymmetry. The first is in resource availability. The incumbent with larger resources can allocate its budget across a range of expenditures and so has more flexibility when it comes to choosing effort, while the challengers are resource constrained and devote all of their limited resources to the conflict. The second is in ways of fighting. The incumbent is locked in by large fixed investments to a particular way of fighting or doing business ${ }^{3}$ and while it has to prepare to be attacked from many directions, the challengers can choose how to attack, having observed the incumbent's vulnerability. This ability to differentiate can make limited resources effective: The 9/11 Commission estimated that the four plane attack cost al Qaeda less than $\$ 500,000$, Keen (2004). In military writing the differentiation is often described on the attrition/maneuver dimension. Luttwak $(1987,96-97)$ notes. 'Under an attritional approach, when the aim is to secure technical advantage by the generous use of resources, the conduct of research and development requires no particular tactical or operational focus: the goal is to obtain the

\footnotetext{
${ }^{3}$ In the case of the US military some evidence for inertia is provided by Trajtenberg (2003) who shows that the shares of US defence R\&D expenditures across different categories have not changed since September 11th, 2001 with $30 \%$ of R\&D expenditures still being allocated to big weapon systems.
} 
"best" systems, which maximise every aspect of performance, subject only to cost ceilings. .... Under a relational-maneuver approach, by contrast, the aim of research and development is precisely to obtain technical abilities that exploit specific enemy vulnerabilities and are congruent with tactics and methods shaped by the same purpose.' Like most military literature, we do not treat ways of fighting, strategies or weapons, as inherently offensive or defensive and separate the way of fighting from the choice to attack or defend. Reiter (1999) discusses this issue. In our model, challengers may differentiate, then not attack or not differentiate then attack.

\subsection{Probability of winning}

The contest success function, or CSF, gives the probability of winning for each party $i=a, b$, as a function of their final stage choices $S_{i}$, attack or defend, their efforts, $e_{a}$ and $e_{b}$, and the challengers' degree of differentiation, $t \geq 0$. The probability of player $i$ winning $P_{i}\left(S_{a}, S_{b}\right)$, depends on the final stage choice of the incumbent, the first term in parenthesis, and of the challengers, second term. Thus $P_{a}(A, D)$ is the probability the incumbent wins if it attacks and the challengers defend and $P_{b}(D, A)$ is the probability the challengers win if the incumbent defends and they attack. If neither side attacks, they get the peacetime shares of the prize $s_{a} \leq 1$ and $s_{b}=1-s_{a}$. The contest success functions are:

$$
\begin{aligned}
P_{a}(A, D) & =\frac{t+e_{a}}{t+e_{b}+e_{a}} . \\
P_{a}(D, A) & =\frac{e_{a}}{t+e_{b}+e_{a}} . \\
P_{a}(A, A) & =\frac{e_{a}}{e_{b}+e_{a}} . \\
P_{a}(D, D) & =s_{a} .
\end{aligned}
$$

with $P_{b}\left(S_{a}, S_{b}\right)=1-P_{a}\left(S_{a}, S_{b}\right)$.

Note that in the formal model the $P(.,$.$) can be treated either as probabilities or as$ shares of the prize. The only difference is expected utility is replaced by utility. Both interpretations are common in the conflict literature.

While CSFs which make the probability of success a function of the ratio of effort by each side are common in the conflict literature, ours differ in allowing the probabilities to 
depend on the attack/defend choices of the two parties and the degree of differentiation by the challengers.

Note that

$$
\begin{aligned}
& P_{b}(D, A) \geq P_{b}(A, A) \geq P_{b}(A, D) \\
& P_{a}(A, D) \geq P_{a}(A, A) \geq P_{a}(D, A) .
\end{aligned}
$$

where equalities apply when there is no differentiation, since the probability of winning will just depend on effort. Differentiation provides an advantage in attack and a disadvantage in defence. Thus, in stage 3, if the incumbent attacks and the challengers defend, differentiation benefits the incumbent; whereas if the incumbent is defending against attack by the challengers, differentiation benefits the challengers. In a mutual attack, differentiation cancels out and the probabilities just depend on relative effort. Differentiation acts as a 'surprise' factor that benefits the party which is on the attack and has the opposite effect to a defensive advantage ${ }^{4}$. Treating maneuver as an example of differentiation, this makes defence more difficult. For example, the technology and tactics of Blitzkrieg, depending on speed and movement, gave the Germans a substantial advantage when they were attacking, but left them at a disadvantage when defending against attack by the Soviets. Luttwak (1987, p99-106) discusses the rewards and risks of Blitzkrieg.

We assume that the status-quo, peacetime, shares of the prize $s_{i}$, are exogenous. In many cases it would in fact be cheaper for the incumbent to bribe the challengers with the promise of a larger third-stage peace-time share rather than to deter, defend or attack, but rarely can an incumbent credibly pre-commit to do so and for commercial incumbents it is usually illegal. We return to this issue in the conclusion.

\subsection{Payoffs and the cost of conflict}

The payoffs are the expected utilities of the parties, $i=a, b$ from their final stage strategies, attack or defend, $S_{i}=A, D$. The expected utility of a party is the probability of winning, $P_{i}\left(S_{a}, S_{b}\right)$ times the shares of the prize, $V$, that is left after the conflict, $\phi_{i}\left(S_{a}, S_{b}\right)$, less

\footnotetext{
${ }^{4}$ Siqueira (2002) includes a defensive advantage to capture the usual military rule of thumb that the attacker needs a local advantage of 3 to 1 , to be sure of winning. In an earlier version of the paper we included such a defensive advantage, all the results here go through as long as the defensive advantage is not too large.
} 
the cost of their effort, $C\left(e_{i}\right)$ :

$$
\begin{aligned}
& E U_{a}\left(S_{a}, S_{b}\right)=P_{a}\left(S_{a}, S_{b}\right) \phi_{a}\left(S_{a}, S_{b}\right) V-C_{a}\left(e_{a}\right), \\
& E U_{b}\left(S_{a}, S_{b}\right)=P_{b}\left(S_{a}, S_{b}\right) \phi_{b}\left(S_{a}, S_{b}\right) V-C_{b}\left(e_{b}\right),
\end{aligned}
$$

The perceived cost of conflict, $1-\phi_{i}\left(S_{a}, S_{b}\right)$, differs between the insurgent and challengers, and by type of conflict. There is a large quantitative literature on how the cost of conflict varies with type of conflict, e.g. inter-state war, intra-state war or terrorist attack. Blomberg, Hess, and Orphanides (2004) and Tavares (2004) examine how the economic costs of terrorist attacks are sensitive to the country's political and economic characteristics. Even were the two sides to agree on the consequences of conflict (destruction of property, lives lost by each side and uninvolved civilians, economic opportunities foregone, loss of autonomy, etc.) they would be unlikely to aggregate them in the same way, particularly where the consequences involve what Bernholz (2004) calls supreme values. A dominant incumbent may attach a high value to their own lives and a low value to opponents lives, e.g. the US in Vietnam, whereas the challengers may attach a low value to their own death and a high value to their opponent's deaths, e.g. suicide bombers. Thus perceptions of the cost of will vary. Tessler and Nachtwey (1998) examine how personal characteristics and religion influence perceptions of the costs and benefits of conflict.

If both parties defend, there is peace, no costs of conflict are incurred and the utilities are $s_{a} V-C_{a}\left(e_{a}\right)$ and $s_{b} V-C_{b}\left(e_{b}\right)$. Since $e_{b}$ is exogenous, we measure the challengers' payoff relative to their constant $\operatorname{costs} C_{b}\left(e_{b}\right)$. We also normalize $V=1$. Table 1 gives the

\begin{tabular}{|c|c|c|c|c|}
\hline$a \backslash b$ & \multicolumn{2}{|c|}{$A$} & \multicolumn{2}{|c|}{$D$} \\
\hline$A$ & $P_{a}(A, A) \phi_{a}(A, A)-C_{a}$, & $P_{b}(A, A) \phi_{b}(A, A)-C_{b}$ & $P_{a}(A, D) \phi_{a}(A, D)-C_{a}$ & $P_{b}(A, D) \phi_{b}(A, D)-C_{b}$ \\
\hline$D$ & $P_{a}(D, A) \phi_{a}(D, A)-C_{a}$ & $P_{b}(D, A) \phi_{b}(D, A)-C_{b}$ & $s_{a}-C_{a}$, & $s_{b}-C_{b}$ \\
\hline
\end{tabular}
expected payoffs for the four possible outcomes.

Table 1. Payoffs

The perceived costs of conflict are crucial because they determine the payoffs to the strategy of each party and thus the potential equilibria. The game we are interested in has a dominant incumbent satisfied with the status quo, scope for attack that destroys resources and defence which reduces destruction and a dissatisfied challenger with an incentive to attack. The assumptions which give such a game are: 
(a) the incumbent enjoys the status quo and so prefers peace to attacking unthreatening challengers,

$$
s_{a}>\phi_{a}(A, D)
$$

which excludes unprovoked attack as a possible equilibrium.

(b) defence reduces the destruction of an attack, so for the incumbent more of the prize is left under $(D, A)$ than $(A, A)$

$$
\phi_{a}(D, A)>\phi_{a}(A, A)
$$

(c) similarly for the challengers

$$
\phi_{b}(D, A)>\phi_{b}(A, A)
$$

(d) the challengers may have an incentive to attack because the proportion of the prize left after they attack is greater than their status quo share

$$
\phi_{b}(D, A)>s_{b} .
$$

The above assumptions allow first, an asymmetric perceived cost of conflict between the different parties and second, a perceived cost of conflict which is sensitive to the conflict type. Support for these assumptions can be found in recent empirical literature on the economic costs of conflict. Blomberg, Hess, and Orphanides (2004) prove although terrorism has a negative effect on growth, this is smaller and less persistent than that associated with external wars.

Note that assumption (a) arises both with large $s_{a}$, the interpretation we emphasise, or small $\phi_{a}(A, D)$, where the cost of attacking challengers is high, e.g. terrorists who can melt away into the community or are located in difficult terrain. Keen (2004) describes the difficulties the US faced in attacking Bin Laden before 9/11. This assumption aims to capture a situation when the incumbent is pleased with the status quo whereas the challengers are not. If the incumbent could credibly threaten unprovoked attack, the challengers would find differentiation less attractive since it turns into a disadvantage when they are being attacked.

Other assumptions would give other games, but these capture the case we are interested in. We treat the perceived cost of conflict, like peace-time shares, as exogenous. Many 
attempts at external conflict resolution are designed to change such perceptions, usually with little success; Bernholz (2004) discusses the difficulties. We return to this issue in the conclusions.

\section{The solution to the game}

In this section we obtain the Subgame Perfect Equilibrium of the game when differentiation is possible and compare it with the case when it is not. We introduce fixed costs of differentiation in the next section.

\subsection{Last stage: simultaneous choice of defence or attack}

In the last stage, effort or differentiation costs do not appear because they are sunk costs by then. Considering the conditions for each of the four possible candidates for a Pure Strategy Nash equilibria in the last stage, we have:

1. MUTUAL ATTACK, $(A, A)$ : For this to be an equilibrium, each party must prefer mutual attack to defending against attack by the other: so the $(A, A)$ payoff to the incumbent is greater than the $(A, D)$ payoff and the $(A, A)$ payoff to the challengers is greater than the $(D, A)$ payoff:

$$
\begin{aligned}
& \phi_{b}(A, A) P_{b}(A, A) \geq \phi_{b}(A, D) P_{b}(A, D) \\
& \phi_{a}(A, A) P_{a}(A, A) \geq \phi_{a}(D, A) P_{a}(D, A)
\end{aligned}
$$

2. PEACE, $(D, D)$ : For this to be an equilibrium, each party's peacetime shares, $s_{a}$ and $s_{b}$, must be greater than the payoffs from attacking:

$$
\begin{aligned}
& s_{b} \geq \phi_{b}(D, A) P_{b}(D, A) \\
& s_{a} \geq \phi_{a}(A, D) P_{a}(A, D)
\end{aligned}
$$

3. DEFENSIVE CONFLICT, $(D, A)$ : For this to be an equilibrium, the challengers must gain by attacking and the incumbent must gain by defending:

$$
\begin{aligned}
s_{b} & \leq \phi_{b}(D, A) P_{b}(D, A) \\
\phi_{a}(D, A) P_{a}(D, A) & \geq \phi_{a}(A, A) P_{a}(A, A)
\end{aligned}
$$


4: UNPROVOKED ATTACK, $(A, D)$ : This cannot be a candidate for Nash Equilibrium as, by assumption (a), $s_{a}>\phi_{a}(A, D)$.

Thus, we are left with three candidates for Nash Equilibrium in the last stage of the game. If differentiation was not possible, then $P_{a}(A, D)=P_{a}(D, A)=P_{a}(A, A)$ and defence would be a dominant strategy for the incumbent, meaning that mutual attack could not be an equilibrium in the final stage. With differentiation, even if assumption (b) were to hold, mutual attack could still be an equilibrium. Attack could be the best response for incumbents when challengers attack, because it neutralizes the advantage that the challengers get from differentiation. However, we shall see that the challengers will limit their differentiation to block the mutual attack equilibrium.

\subsection{Stage 2: choice of differentiation by the challengers}

In the second stage, the challengers choose to how much to differentiate conditional on the incumbent's choice of effort $e_{a}$. Assumption (a) $s_{a}>\phi_{a}(A, D)$, excludes $(A, D)$ as an equilibrium and we need to determine which of the other equilibria the challengers will want to implement, through their choice of $t\left(e_{a}\right)$. Since $P_{b}(A, A)<P_{b}(D, A)$ and $\phi_{b}(A, A)<$ $\phi_{b}(D, A)$ it follows that $P_{b}(A, A) \phi_{b}(A, A)<P_{b}(D, A) \phi_{b}(D, A)$, and so challengers will prefer $(D, A)$ to $(A, A)$. Since differentiation is assumed costless, ${ }^{5}$ the challengers will choose it such that in the final stage the incumbent prefers $(D, A)$ to $(A, A)$. This requires ${ }^{6}$

$$
P_{a}(A, A) \phi_{a}(A, A) \leq P_{a}(D, A) \phi_{a}(D, A)
$$

Substituting for $P_{a}(D, A)$ and $P_{a}(A, A)$ from (1) and solving for $t=t_{1}\left(e_{a}\right)$ say, the challengers' differentiation is given by

$$
t \leq t_{1}\left(e_{a}\right)=\frac{\left(e_{a}+e_{b}\right)\left[\phi_{a}(D, A)-\phi_{a}(A, A)\right]}{\phi_{a}(A, A)}
$$

This choice will block $(A, A)$ as a possible third stage equilibrium leaving only two possibilities $(D, A)$ and $(D, D)$.

Suppose the challengers prefer $(D, A)$ in the third stage, then they will choose $t$ to:

$$
\max _{\{t\}} \phi_{b}(D, A) P_{b}(D, A)=\phi_{b}(D, A) \frac{t+e_{b}}{t+e_{b}+e_{a}}
$$

\footnotetext{
${ }^{5}$ In section 4, we relax this assumption.

${ }^{6} \mathrm{We}$ assume in the case of equal payoffs that players prefer defence to attack and 'give peace a chance'.
} 
subject to (6). Since the payoff is increasing in $t,(6)$ must bind and $t=t_{1}\left(e_{a}\right)$ is optimal if $(D, A)$ is chosen.

Suppose the challengers prefer $(D, D)$ in the third stage, $(D, D)$ will be induced iff $t$ is such that

$$
P_{b}(D, A) \phi_{b}(D, A)=\frac{\left(t+e_{b}\right) \phi_{b}(D, A)}{t+e_{b}+e_{a}} \leq s_{b}
$$

giving a threshold level of differentiation

$$
t=\left\{\frac{e_{a} s_{b}}{\phi_{b}(D, A)-s_{b}}-e_{b}\right\}=t_{2}\left(e_{a}\right)
$$

below which challengers prefer $(D, D)$ to $(D, A)$. Taking these results together we have:

Proposition 1. There are only two candidates for unique pure strategy Nash Equilibrium in stage 3 of the conflict game: $(D, A)$ and $(D, D)$. Given $e_{a}$, the challengers will induce $(D, A)$ and block $(A, A)$ by choosing a level of differentiation $t=t_{1}\left(e_{a}\right)$ iff $t_{1}\left(e_{a}\right)>t_{2}\left(e_{a}\right)$ where functions $t_{1}\left(e_{a}\right)$ and $t_{2}\left(e_{a}\right)$ are given by (6) and (7) respectively. If this condition is not satisfied (i.e., iff $t_{1}\left(e_{a}\right) \leq t_{2}\left(e_{a}\right)$ ) the challengers will induce the peace equilibrium $(D, D)$.

There are now two cases to consider depending on whether

$$
\frac{d t_{1}\left(e_{a}\right)}{d e_{a}}=\frac{\phi_{a}(D, A)-\phi_{a}(A, A)}{\phi_{a}(A, A)} \leq \text { or }>\frac{d t_{2}\left(e_{a}\right)}{d e_{a}}=\frac{s_{b}}{\phi_{b}(D, A)-s_{b}}
$$

i.e., whether

$$
\left(\phi_{b}(D, A)-s_{b}\right) \phi_{a}(D, A) \leq \text { or }>\phi_{a}(A, A) \phi_{b}(D, A)
$$

Case 1: Equilibria $(D, A)$ and $(D, D)$ are feasible.

Here $\phi_{b}(D, A)-s_{b}$ (challenger payoff to attack less status quo payoff) is sufficiently small relative to $\phi_{a}(A, A) \frac{\phi_{b}(D, A)}{\phi_{a}(D, A)}$ that

$$
\left(\phi_{b}(D, A)-s_{b}\right) \phi_{a}(D, A)<\phi_{a}(A, A) \phi_{b}(D, A)
$$

At the intersection $t_{1}\left(e_{a}\right)=t_{2}\left(e_{a}\right)$ incumbent effort, decided at stage 1 , is $e_{a}=e_{a}^{*}$ say, where

$$
e_{a}^{*}=\frac{e_{b} \phi_{a}(D, A)\left(\phi_{b}(D, A)-s_{b}\right)}{\phi_{b}(D, A) \phi_{a}(A, A)-\left(\phi_{b}(D, A)-s_{b}\right) \phi_{a}(D, A)}
$$

Condition (10) ensures that $e_{a}^{*} \in(0, \infty)$. If $e_{a} \geq e_{a}^{*}$, then $t_{1}\left(e_{a}\right) \leq t_{2}\left(e_{a}\right)$ resulting in peace $(D, D)$, so the challengers attacks are deterred. If $e_{a}<e_{a}^{*}$ then $t_{1}\left(e_{a}\right)>t_{2}\left(e_{a}\right)$ 
and $(D, A)$ is induced. Suppose the costs of conflict in equilibrium $(D, A)$ are the same for both players $\left(\phi_{a}(D, A)=\phi_{b}(D, A)\right)$. Then if the cost of conflict to the challengers $\left(1-\phi_{b}(D, A)\right)$ falls; and/or their status quo payoff $s_{b}$ falls; and/or the cost of mutual attack to the incumbent $\left(1-\phi_{a}(A, A)\right)$ rises; then $e_{a}^{*}$ rises. This makes attaining peace more costly to the incumbent: more effort is required to induce it. Figure 1 illustrates this case.

\section{Case 2: Only equilibrium $(D, A)$ is feasible.}

In this case (10) no longer holds. If $\left(\phi_{b}(D, A)-s_{b}\right) \phi_{a}(D, A)=\phi_{a}(A, A) \phi_{b}(D, A)$ then the $t_{1}\left(e_{a}\right)$ and $t_{2}\left(e_{a}\right)$ curves are parallel and $e_{a}^{*}=\infty$. If $\left(\phi_{b}(D, A)-s_{b}\right) \phi_{a}(D, A)>$ $\phi_{a}(A, A) \phi_{b}(D, A)$ the curves intersect at $e_{a}^{*}<0$ as illustrated in Fig. 2. In both cases, there is no level of effort by the incumbent that can induce $(D, D)$. If the incentives for the challenger to attack are high because of a sufficiently low cost of conflict and a low payoff at the status quo, and there is a low incentive for the incumbent to engage in all-out-attack $(A, A)$, then the peace equilibrium $(D, D)$ is not feasible.

Summarizing these results we have:

Proposition 2. If condition (10) holds then there exists a threshold level of effort by the incumbent $e_{a}^{*}$ given by (11) such that for $e_{a}<e_{a}^{*}$ equilibrium $(D, A)$ is induced at stage 3, whilst for $e_{a} \geq e_{a}^{*}$ it is the peace equilibrium $(D, D)$ that is induced. If (10) does not hold then $(D, D)$ is unfeasible and only one equilibrium $(D, A)$ is possible at stage 3.

With differentiation, peace may not be possible. If peace is possible, there is a threshold level of incumbent effort below which attack is induced. Above this threshold, the challengers are deterred and peace results.

\subsection{Stage 1: Choice of effort by incumbent}

Through its choice of effort, the incumbent determines which of the two remaining candidates, $(D, D)$ and $(D, A)$, emerges as the unique equilibrium in stage 3 . The incumbent can induce the peace equilibrium $(D, D)$ by choosing $e_{a} \geq e_{a}^{*}$ in case 1 but only $(D, A)$ is possible in case 2 . Consider first the possibility of stage 3 equilibrium $(D, A)$ obtained by choosing $e_{a}$ to

$$
\max _{\left\{e_{a}\right\}} E U_{a}(D, A)=\phi_{a}(D, A) P_{a}(D, A)-C\left(e_{a}\right)
$$


subject to $e_{a}<e_{a}^{*}$. Substituting for $P_{a}(D, A)$ from (1), and putting $t=t_{1}\left(e_{a}\right)$, the optimal choice of differentiation in stage 2 by the challengers if $(D, A)$ is induced at stage 3 , we get:

$$
E U_{a}(D, A)=\frac{\phi_{a}(A, A) e_{a}}{\left(e_{a}+e_{b}\right)}-C_{a}\left(e_{a}\right)
$$

which is equal to the incumbent's expected utility if $(A, A)$ was the equilibrium. This is because the incumbent anticipates that in the following stage the challengers will choose the degree of differentiation that just makes the incumbent prefer $(D, A)$ to $(A, A)$.

The first order condition for an internal solution, which implicitly defines the optimal level of conflict effort in the presence of differentiation, $e_{a}^{(D, A)}<e_{a}^{*}$ say, is

$$
\frac{d E U_{a}(D, A)}{d e_{a}}=\frac{\phi_{a}(A, A) e_{b}}{\left(e_{a}+e_{b}\right)^{2}}-\frac{d C_{a}\left(e_{a}\right)}{d e_{a}}=0 .
$$

Now suppose the incumbent chooses to induce $(D, D)$ which is only possible in case 1. This is achieved by setting $e_{a}=e_{a}^{*}$, the level just sufficient to deter attack at stage 3 . Since effort is costly no more effort will be exerted. The payoff in this equilibrium is given by

$$
E U_{a}(D, D)=s_{a}-C_{a}\left(e_{a}^{*}\right)
$$

which should be compared to that in $(D, A)$ given by (13) with $e_{a}=e_{a}^{(D, A)}<e_{a}^{*}$.

Finally, note that if there is no internal solution in $(13) e_{a}^{(D, A)}$ will be set just below $e_{a}^{*}$.

\subsubsection{Comparison with the no-differentiation case}

We now compare the results above with those where differentiation is not possible and there are only two stages to the game. The equivalent condition for the optimal conflict effort $\left[e_{a}^{(D, A))}\right]_{t=0}$, would be:

$$
\frac{d E U_{a}(D, A)}{d e_{a}}=\frac{\phi_{a}(D, A) e_{b}}{\left(e_{b}+e_{a}\right)^{2}}-\frac{d C_{a}\left(e_{a}\right)}{d e_{a}}=0 .
$$

Since by assumption (b), $\phi_{a}(D, A)>\phi_{a}(A, A)$, comparison of (14) and (16) gives:

Proposition 3. If the incumbent prefers $(D, A)$, when the challengers can differentiate, the outcome is a lower level of effort by the incumbent than when the challengers cannot; i.e., $e_{a}^{(D, A)}<\left[e_{a}^{(D, A)}\right]_{t=0}$. 
With differentiation, the effectiveness of effort is reduced, military expenditure provides less security, so the incumbent spends less on it.

Now consider the possibility of peace. In order to induce $(D, D)$ with no differentiation, from (3) incumbent effort must deter the challengers, make them prefer defence to attack; i.e., to satisfy

$$
\phi_{b}(D, A) P_{b}(D, A)=\phi_{b}(D, A) \frac{e_{b}}{e_{b}+e_{a}} \leq s_{b} \Rightarrow\left[e_{a}^{(D, D)}\right]_{t=0} \geq \frac{e_{b}\left(\phi_{b}(D, A)-s_{b}\right)}{s_{b}}>0
$$

Given that $s_{b}<\phi_{b}(D, A)$, by assumption (d), some effort will be required to ensure this.

In case 1 (but not case 2 where peace is not feasible with differentiation) we can compare $\left[e_{a}^{(D, D)}\right]_{t=0}$ with $e_{a}^{(D, D)}=e_{a}^{*}$ with $e_{a}^{*}$ given by (11). Writing the latter as

$$
e_{a}^{*}=\frac{e_{b}\left(\phi_{b}(D, A)-s_{b}\right)}{s_{b}+\phi_{b}(D, A)\left(\frac{\phi_{a}(A, A)}{\phi_{a}(D, A)}-1\right)}
$$

and using $\phi_{a}(A, A)<\phi_{a}(D, A)$ by assumption (b), we arrive at the result $\left[e_{a}^{(D, D)}\right]_{t=0}<$ $e_{a}^{(D, D)}$.

Proposition 4. If, in case 1 , the incumbent prefers $(D, D)$, when the challengers can differentiate, the outcome is a higher level of effort by the incumbent than when the challengers cannot; i.e., $e_{a}^{(D, D)}>\left[e_{a}^{(D, D)}\right]_{t=0}$. In case 2, $(D, D)$ is feasible only without differentiation.

If, with differentiation, the incumbent can set its effort to implement peace (i.e., case 1), this level of effort will be larger than the level required to implement peace in the no-differentiation case. Because the challengers have more incentive to attack when they can differentiate, the incumbent has to expend more effort to deter attack.

\subsubsection{The incumbent's decision to induce $(D, D)$ or $(D, A)$}

This choice is only relevant to case 1 , since in case $2(D, D)$ is not feasible. The incumbent will induce peace if it gives greater expected utility than defending against attack, $E U_{a}\left(e_{a}^{(D, D)}\right)>E U_{a}\left(e_{a}^{(D, A)}\right)$. From (13) and (15), the condition for this is

$$
s_{a}-\frac{\phi_{a}(A, A) e_{a}^{(D, A)}}{\left(e_{a}^{(D, A)}+e_{b}\right)}>C_{a}\left(e_{a}^{(D, D)}\right)-C_{a}\left(e_{a}^{(D, A)}\right)
$$


The left-hand-side of (19) gives the benefits of the status quo relative to a share of the prize following mutual attack. If we impose a further assumption (e) that the incumbent's share of resources is higher in peace than with defensive attack; i.e.,

$$
s_{a}>\phi_{a}(D, A)
$$

then these benefits are positive since the above, together with assumption (b), implies $s_{a}>\phi_{a}(A, A)$ and $\frac{e_{a}^{(D, A)}}{\left(e_{a}^{(D, A)}+e_{b}\right)}<1$. The right-hand-side of (19) gives the costs to the incumbent of inducing peace, which are positive since $e_{a}^{(D, D)}>e_{a}^{(D, A)}$ for conflict to be feasible. The incumbent's decision depends on the interplay between these benefits and costs (in particular on whether (20) holds) and the opportunity cost of effort $C_{a}\left(e_{a}\right)$. Note that, if $s_{a}>\phi_{a}(D, A)$ a necessary condition for the incumbent to prefer conflict will be that there is an internal solution for $e_{a}^{(D, A)}$, since otherwise the difference between the cost of peace and conflict will tend to zero.

We now consider whether the challengers ability to differentiate increases or decreases the prospects of peace $(D, D)$. We know in case 2 that differentiation may make peace impossible, as shown in Figure 3. In case 1, the analysis is more complex. Starting from a situation in which there is no-differentiation and the incumbent prefers to induce peace. Allowing differentiation means that it takes the incumbent more effort to deter the challengers, i.e. to persuade them not to attack, $\left[e_{a}^{(D, D)}\right]_{t=0}<e_{a}^{(D, D)}$. Differentiation also reduces the incumbent's incentive to cut its effort to just above the level that would provoke mutual attack $(A, A)$ meaning that $e_{a}^{(D, A)}<\left[e_{a}^{(D, A)}\right]_{t=0}$. It is, therefore, more likely that an internal solution for $e_{a}^{(D, A)}$ is achieved with differentiation. As was the case when $s_{a}>\phi_{a}(D, A)$, a necessary condition for the incumbent to prefer conflict is an internal solution for $e_{a}^{(D, A)}$.

Starting from peace the introduction of the ability to differentiate may result in conflict. In general however, the impact of differentiation on the possibility of peace is ambiguous. Although the cost of inducing peace (the right hand side of (19)) rises with differentiation, so does the relative benefit of peace (the left hand side of (19)). The quantitative evidence suggests that differentiation does increase the probability of war. Reiter (1999) finds that when states differentiate strategy, one adopts maneuver the other attrition, disputes are much more likely to escalate to war than when both adopt maneuver or both attrition. 


\section{The game with fixed costs of differentiation}

The previous section analyzed the model with and without differentiation. This section integrates the two by introducing a fixed cost of differentiation. We assume there is a cost $F$ of choosing to differentiate (this is similar to set-up costs in location models). For high $F$ challengers do not differentiate, while for low $F$ they do, and at the switch point there is a discontinuity in the incumbent payoff. We now proceed to solve the game backwards using the results from previous sections.

The last stage of the game is unchanged, since by then $F$ is sunk and differentiation, if any, is a given parameter. In the second stage of the game, the challengers choose the degree of differentiation $t$. In previous sections, we obtained the optimal degree of differentiation, should the challengers decide to differentiate $t_{1}$. Now, if fixed costs are sufficiently high, the challengers may not differentiate, even if they expect to attack in the final stage of the game. The payoff from differentiating is higher than that of not differentiating (for a given level of the incumbent's effort) if:

$$
\phi_{b}(D, A)\left[P_{b}(D, A)\right]_{t=t_{1}}>\phi_{b}(D, A)\left[P_{b}(D, A)\right]_{t=0} .
$$

Therefore, to persuade the challengers not to differentiate (even when expecting $(D, A)$ ), fixed costs $F$, need to be bigger than $F^{*}$, defined as:

$$
F^{*}=\phi_{b}(D, A)\left[P_{b}(D, A)\right]_{t=t_{1}}-\phi_{b}(D, A)\left[P_{b}(D, A)\right]_{t=0}
$$

Note that $F^{*}$ is increasing in the incumbent's effort ${ }^{7}$.

To ensure that the challengers prefer peace $(D, D)$, incumbent effort must ensure that they have no incentive to attack, either with or without differentiation. Therefore, the peace condition is:

${ }^{7}$ Substituting for $t_{1}$,

$$
F^{*}=\frac{\phi_{b}(D, A) e_{a}}{\left(e_{a}+e_{b}\right)} \frac{\left(\phi_{a}(D, A)-\phi_{a}(A, A)\right)}{\phi_{a}(D, A)}
$$

Therefore, $\frac{\partial F^{*}}{\partial e_{a}}>0$. 


$$
s_{b} \geq \max \left\{\phi_{b}(D, A)\left[P_{b}(D, A)\right]_{t=t_{1}}-F, \phi_{b}(D, A)\left[P_{b}(D, A)\right]_{t=0}\right\} .
$$

The payoff for the challengers if they do not attack needs to be higher than the maximum of their payoffs when they attack, whether or not they differentiate ${ }^{8}$. Figure 4 provides a graphical representation of this condition (21) as a function of incumbent effort ${ }^{9}$. To understand Figure 4, note that the two terms in the right hand side of (21) intersect at a level of incumbent effort which we denote $e_{a}^{I}$. This effort is zero for zero fixed costs and increases with $F$. If the fixed costs were sufficiently high, not differentiating would be better for the challengers, irrespective of effort levels (see Appendix for details).

The incumbent effort which makes the challengers indifferent between differentiating or not $e_{a}^{I}$, is a new parameter which results from the fixed cost of differentiation. As long as this cost is positive, it may be possible for the incumbent to prevent differentiation, even if conflict cannot be prevented. This level of effort connects with the analysis of previous section, as it introduces a discontinuity point in the conflict payoff for the incumbent, which jumps from the differentiation payoff to the non-differentiation payoff if the incumbent's effort falls bellow $e_{a}^{I}$ (see for instance, bottom graph in Fig. 5).

Thus we have:

Proposition 5. Increases in fixed differentiation costs $F$ will reduce the level of conflictpreventing effort $e_{a}^{(D, D)}$, until it reaches the conflict preventing effort without technology differentiation $\left[e_{a}^{(D, D)}\right]_{t=0}$.

Proof: See Appendix.

Figure 4 illustrates this proposition. It shows the minimum level of incumbent effort required to prevent conflict $e_{a}^{(D, D)}$, for a given peacetime payoff for the challengers $s_{b}$. It also shows the impact of an increase in the fixed cost from, $F=0$ to $F=\widehat{F}$, which is the fixed cost that makes the conflict preventing effort with and without differentiation coincide.

In order to understand the above result note that:

\footnotetext{
${ }^{8}$ Note that if $\phi_{b}(D, A)\left[P_{b}(D, A)\right]_{t=t_{1}}-F>\phi_{b}(D, A)\left[P_{b}(D, A)\right]_{t=0}$, the challengers will differentiate only if $s_{b}<\phi_{b}(D, A)\left[P_{b}(D, A)\right]_{t=t_{1}}-F$. Otherwise, they will not differentiate and therefore, there will be no conflict, even if $s_{b}<\phi_{b}(D, A)\left[P_{b}(D, A)\right]_{t=t_{1}}$.

${ }^{9}$ For clarity we use linear functions to represent terms 1 and 2 of the right hand side of the conflict preventing condition. In fact, they are convex in the incumbent's effort.
} 
- First, increases in $F$, starting at $F=0$, will reduce the differentiation payoff of the challengers, therefore causing downward shifts to the function represented by the first term of the peace condition. This will reduce the minimal conflict-preventing effort $e_{a}^{(D, D)}$ (since conflict now becomes a relatively less attractive option for the challengers) until the shift reaches the intersection between the other two functions: the non differentiation conflict payoff and the peace payoff $s_{b}$. This will happen at a cost level which we denote $\widehat{F}$.

- Second, if $F>\widehat{F}$, the conflict-preventing effort will coincide with the one obtained when differentiation is not possible $\left[e_{a}^{(D, D)}\right]_{t=0}$. Therefore, increases in $F$ beyond $\widehat{F}$ will not affect the level of conflict-preventing effort.

Having analyzed the condition for incumbent effort to prevent conflict, we now analyze the impact of $F$ on optimal incumbent effort should it decide not to prevent conflict. In finding the optimal effort, we must take account of the fact that the incumbent's payoff function is likely to be discontinuous when $(D, A)$ is preferred. Figs 5 and 6 , show the incumbent's expected payoff functions when the $(D, A)$ equilibrium is expected, for both the differentiation and no differentiation cases (analyzed in previous sections). With fixed costs, the relevant expected payoff function is now shown by the thicker discontinuous curves, where the point of discontinuity is the incumbent's level of effort at which the first and second terms in condition (21) intersect, $e_{a}^{I}$. Higher levels of effort will make the challengers prefer to differentiate and therefore the payoff with differentiation becomes the relevant one, but when $F$ is big enough, differentiation will not occur even when conflict is expected. This situation is shown in Fig. 5, which corresponds to our earlier analysis without differentiation. If the fixed cost of effort $F$ is sufficiently low, however, the optimal level of defensive effort $e_{a}^{(D, A)}$ will not prevent differentiation from taking place, as shown in Fig. 6. Finally, it is worth noting that starting from a sufficiently high $F$, decreases in $F$ can force a reduction in the optimal defensive effort which follow $e_{a}^{I}$ and do not induce differentiation. However, as illustrated in Fig. 7, there will be a point where attempts to prevent differentiation stop and the effort level will jump up to the optimal differentiation effort level analyzed in previous sections. Further decreases in $F$ will then have no impact on the optimal defensive effort $e_{a}^{(D, A)}$. We can summarize the discussion in the following proposition: 
Proposition 6. In the presence of fixed differentiation costs, it may be better for the incumbent to reduce defensive effort in order to discourage differentiation. The choice for the incumbent will be between preventing conflict by deterring attack or defending against an attack without differentiation. However, if differentiation costs are low enough, the choice, as in the case without fixed differentiation costs, will be between preventing conflict by sufficient effort or defending against an attack with differentiation.

Finally consider the impact of decreases in $F$ on the chance of peace. Starting from peace, easier differentiation (lower $F$ ) increases the chance that the necessary condition for conflict, under the assumption $s_{a}>\phi_{a}(D, A)$, will be satisfied, $e_{a}^{(D, A)}<e_{a}^{(D, D)}$. There is, however, one point at which decreases in $F$ force an upward jump in effort, when the incumbent gives up preventing differentiation. After that, the incumbent's expected payoff is not affected by $F$, though $F$ continues to affect the peace payoff negatively until $e_{a}^{I}=0$. Also, as shown above, peace may not be feasible, below a critical value of $F$.

\section{Conclusion}

In this paper, we have presented a simple model of asymmetric conflict in which big guy, the incumbent, makes a choice to which it becomes locked in, while the little guys, the challengers, can choose to differentiate their technology or tactics to exploit the incumbent's vulnerabilities. Although simple, this idea describes a number of interesting military, commercial, and legal conflicts. It explains how the possibility of differentiation can give the little guys an edge and can increase their probability of winning should they attack. Without differentiation the incumbent can always deter the challengers by sufficient effort, but with differentiation attack may be inevitable and deterrence may be impossible, whatever the incumbent's investment in effort. In addition, since differentiation reduces the effectiveness of the incumbent's effort if conflict comes, the incumbent's effort will be lower with differentiation than without it.

The ability to differentiate has important implications for incumbents as it suggests they now face a difficult dilemma, the more effort they invest, the more incentive the challengers have to differentiate and so they can easily push the challengers to adopt more dangerous tactics against them. But the challengers have to limit differentiation to avoid provoking too damaging a retaliation. These results seem consistent with the some of 
the existing empirical literature on the analysis of the causes of conflict, e.g. see Reiter (1999). They also seem consistent with the pattern of nuclear proliferation. In the early 1960s many predicted 25 to 30 states with nuclear weapons by 2000 . This did not happen because many states capable of building nuclear weapons, decided that it would be too provocative. Kase (2001) discusses a 1968/70 Japanese report that concluded that it would be unwise for Japan to develop nuclear weapons because to do so would alarm not only China, but also the US and USSR and leave Japan vulnerable to a nuclear attack. For isolated states, like Israel and South Africa, the calculations were quite different. GarciaAlonso and Smith (2005) discuss this case in more detail.

Our model has a number of policy implications. The incumbent can make differentiation less likely if it can increase the fixed costs of differentiation, e.g. through controls on the diffusion of particular technologies. Nevertheless, the potential for differentiation means that any dominant power, is not necessarily safe from challengers and it increases the need for non military methods to achieve peace. Non-military incentives are discussed in more detail by Frey and Luechinger (2003) and Bernholz (2004). In the context of our model, the non-military methods correspond to changing the peacetime shares or perceived costs of conflict, which we have treated as exogenous. In many cases, if the incumbent could credibly pre-commit to increase the peace-time shares of the challengers, it would wish to do so, as this would be cheaper than either the effort required to deter the challengers or the cost of conflict. Real conflicts are often protracted because neither side believes the other's promises and it often takes a third party guarantor to resolve the conflict. Such guarantors may be hard to find.

An important parameter in our model is the perceived costs of conflict, changes to this parameter may also change the chances of peace. As already mentioned, a recent empirical literature analyzes the determinants of the costs of conflict, interestingly they prove that it is richer countries with a lower cost of terrorist attacks which are more prone to suffering these attacks (see Blomberg, Hess, and Orphanides (2004), this seems consistent with our model.

Sandler and Enders (2004) suggest that a possible way to counteract terrorist attacks using differentiation is to follow the differentiation path of the challenger, however, they also argue (see also Enders and Sandler (1993)) that, in the face of this terrorists simply 
tend to differentiate again (different target or different tactic). In our paper, we keep the technological choice of the incumbents as fixed.

Although the model is simple, the calculations the contestants are required to make are quite complicated and depend on their ability to evaluate the probabilities and the costs of conflict to their opponent. We have assumed that contestants have complete information about all probabilities and payoffs, but our results are quite fragile. The optimum effort or differentiation is often a boundary solution; e.g. if the challengers decide to attack, they will set differentiation at just the level where the incumbent is indifferent between defending and attacking. In such cases, small errors of calculation can cause catastrophe for either side. This is, however, a realistic feature of such conflicts: big decisions turn on difficult calculations about the opponents expected payoff and the model brings this out. Once one allows for asymmetric information, issues of signalling become important. A number of papers within the terrorism literature have used models of incomplete information. Lapan and Sandler (1993) and Overgaard (1994) present an attack by a terrorist group as a signal of the terrorist effort. The introduction of such type of asymmetric information in our model could be an interesting future line of research.

We have imposed a number of assumptions on the cost of conflict, which defined the asymmetric warfare game. But one could look at other games and ask, for instance, under what circumstances would an incumbent want to attack a non-threatening challenger. Our model provides a way to address that question. Essentially, powerful incumbents never feel safe, because they do not know how the little guys will attack them, therefore they may be pre-disposed to take any action that may negate the threat. In our model, the contestants decide to attack or defend simultaneously, we think this is a realistic representation, since in reality neither side can guarantee to get their retaliation in first. However, the fact that we have a one shot static game is a restrictive assumption. Allowing for a dynamic game with multiple interaction between parties would introduce the possibility of cycles: the challengers displace the incumbents, become the new incumbents and are themselves challenged. Also, in a dynamic context one could study the possibility that the perceived costs of conflict, which we take as exogenous, may vary and therefore, affect the chances of peace. Another simplifying assumption in our model is that we do not allow for a defensive advantage on the side of the defensive party, our purpose was to keep the model reasonably 
simple, our results would still stand if we introduced a small defensive advantage. Finally, unlike Sandler and Enders (2004), our model only has one incumbent and therefore, we do not analyze possible benefits to incumbents who face common contestants to coordinate the design of their policies. 


\section{Appendix 1: Graphical representation of peace condition with fixed costs.}

Substituting for $t_{1}=\left(e_{a}+e_{b}\right) \frac{\phi_{a}(D, A)-\phi_{a}(A, A)}{\phi_{a}(A, A)}$, the peace condition can be written as:

$$
s_{b} \geq \max \left\{\phi_{b}(D, A) \frac{\phi_{a}(D, A)\left(e_{a}+e_{b}\right)-\phi_{a}(A, A) e_{a}}{\phi_{a}(D, A)\left(e_{a}+e_{b}\right)}-F, \quad \phi_{b}(D, A) \frac{e_{b}}{e_{b}+e_{a}}\right\}
$$

Note that,

The difference between the first and second term on the R.H.S. is increasing in incumbent effort,

$$
\begin{aligned}
& \frac{\partial\left(\phi_{b}(D, A) \frac{\phi_{a}(D, A)-\phi_{a}(A, A)}{\phi_{a}(D, A)} \frac{e_{a}}{\left(e_{a}+e_{b}\right)}\right)}{\partial e_{a}} \\
= & \phi_{b}(D, A) \frac{\phi_{a}(D, A)-\phi_{a}(A, A)}{\phi_{a}(D, A)} \frac{e_{b}}{\left(e_{a}+e_{b}\right)^{2}}>0,
\end{aligned}
$$

and both terms intersect at $e_{a}$ defined as

$$
e_{a}^{I}=\frac{F e_{b}}{\phi_{b}(D, A) \frac{\phi_{a}(D, A)-\phi_{a}(A, A)}{\phi_{a}(D, A)}-F} .
$$

This is zero for zero fixed cost and increases with $F$.

Note that if

$$
F>\phi_{b}(D, A) \frac{\phi_{a}(D, A)-\phi_{a}(A, A)}{\phi_{a}(D, A)},
$$

not differentiating would always be better for the challengers.

\section{Appendix 2: Proof of Proposition 5.}

First, note that increases in $F$, starting at $F=0$, will cause downward shifts to the function represented by the first term of the peace condition (21). This will reduce the minimal conflict-preventing effort $e_{a}^{(D, D)}$, until the shift reaches the intersection between the other two functions: the second term of the of the peace condition and $s_{b}$. This intersection will happen at $\widehat{F}$, defined by

$$
\phi_{b}(D, A) \frac{e_{b}}{e_{b}+e_{a}^{I}}=s_{b}
$$


where, substituting for $e_{a}^{I}$ we get

$$
\begin{gathered}
s_{b}=\frac{\phi_{b}(D, A)\left[\phi_{a}(D, A)-\phi_{a}(A, A)\right]-\phi_{a}(D, A) F}{\phi_{a}(D, A)-\phi_{a}(A, A)} \Longleftrightarrow \\
\widehat{F}=\frac{\left(\phi_{a}(D, A)-\phi_{a}(A, A)\right)}{\phi_{a}(D, A)}\left[\phi_{b}(D, A)-s_{b}\right] .
\end{gathered}
$$

Any increase in $F$ within the $[0, \widehat{F}]$ interval will cause the conflict-preventing effort $e_{a}^{(D, D)}$ to decrease. The conflict-preventing condition in that interval must ensure:

$$
s_{b} \geq \phi_{b}(D, A) \frac{\phi_{a}(D, A)\left(e_{a}+e_{b}\right)-\phi_{a}(A, A) e_{a}}{\phi_{a}(D, A)\left(e_{a}+e_{b}\right)}-F .
$$

Therefore,

$$
e_{a}^{(D, D)}=\frac{e_{b} \phi_{a}(D, A)\left(\phi_{b}(D, A)-s_{b}-F\right)}{\phi_{b}(D, A) \phi_{a}(A, A)-\left(\phi_{b}(D, A)-s_{b}\right) \phi_{a}(D, A)+F \phi_{a}(D, A)}
$$

which is clearly decreasing in $F$.

Second, if $F \geqslant \widehat{F}$, the conflict-preventing effort will coincide with the one obtained when differentiation was not possible,

$$
\left[e_{a}^{(D, D)}\right]_{t=0}=\frac{e_{b}\left(\phi_{b}(D, A)-s_{b}\right)}{s_{b}} .
$$

Therefore, increases in $F$ beyond $\widehat{F}$ will not affect the level of conflict-preventing effort.

\section{Acknowledgements}

We are grateful to the ESRC for support under grant R00239388 and to two referees, Parimal Bag and Sandeep Kapur for comments on an earlier version.

\section{References}

Abernathy, W. J. (1978) The Productivity Dilemma: Roadblock to Innovation in the Automobile Industry, Johns Hopkins Press.

Arreguin-Toft, A. (2001) How the weak win wars. International Security, 26, 1, $93-128$. 
Bernholz, P. (2004) Supreme values as the basis for terror. European Journal of Political Economy, 20, 317-33.

Blomberg, S. B., Hess, G. D., and Orphanides, A. (2004) The macroeconomic consequences of terrorism. Journal of Monetary Economics, 51, 1007-32.

Bresnahan, T. F. and Greenstein, S. (1999) Technological competition and the structure of the computer industry, Journal of Industrial Economics, 47, 1-40.

Chen, Y. (2000) Strategic bidding by potential competitors: will monopoly persist? Journal of Industrial Economics, 48, 2, 161-175.

Collier, P. and Hoeffler, A. (1998) On economic causes of civil war, Oxford Economic Papers, 50, 563-73.

Enders, W. and Sandler, T. (1993) The Effectiveness of Antiterrorism Policies: A Vector-Autoregression-Intervention Analysis, American Political Science Review 87, 4, $829-44$.

Enders, W. and Sandler, T. (2004) What do we know about the substitution effect in transnational terrorism? In: Andrew Silke (ed.) Terrorism Research. London: Frank Cass.

Frey, B. S. and Luechinger, S. (2003) How to fight terrorism: alternatives to deterrence, Defence and Peace Economics, August, 237-50.

Garcia-Alonso, M. C. and Smith, R. (2005) The economics of arms export controls in The Future of Multilateral Nonproliferation Export Controls, edited by Daniel H. Joyner. Forthcoming.

Grossman, H. I. (1991) A general equilibrium model of insurrections, American Economic Review, 81, 912-21.

Grossman, H. I. and Kim, M. (1995) Swords or plowshares? A theory of the security claims to property, Journal of Political Economy, 103, 1275-88.

Hirshleifer, J. (2001) The Dark Side of the Force, Economic Foundations of Conflict Theory, Cambridge University Press.

Intriligator, M. (1975) Strategic considerations in the Richardson model of arms races. Journal of Political Economy, 83, 339-53.

Kase, Y. (2001) The costs and benefits of Japan's nuclearization: an insight into the 1968/70 internal report, The Nonproliferation Review, 8, 2, 55-68. 
Keen, T. H. (2004) The 9/11 Commission Report. Final Report of the National Commission on Terrorist Attacks upon the United States, www.9-11commission.gov.

Lapan, H. E. and Sandler, T. (1993) Terrorism and signalling. European Journal of Political Economy, 9, 383-97.

Leibowitz, S. J. and Margolis, S.E. (1999) Winners, Losers \& Microsoft, The Independent Institute, Oakland CA.

Luttwak, E. N. (1987) Strategy: The Logic of War and Peace. Cambridge, M.A. Belknap Press.

Newman, N. J. (2000) Asymmetric threats to British Military Intervention Operations, Whitehall Paper 49, Royal United Services Institute.

Overgaard, P. B. (1994) Terrorist attacks as a signal of resources. Journal of Conflict Resolution, 38, 452-78.

Reiter, D. (1999) Military strategy and the outbreak of international conflict: quantitative empirical tests, 1903-1992. The Journal of Conflict Resolution, 43, 3, 366-87.

Rotte, R. and Schmidt, C. M. (2003) On the production of victory: empirical determinants of battlefield success in modern war, Defence and Peace Economics, 14, $175-93$.

Sandler, T. and Arce, M. D. G. (2003) Terrorism and game theory. MIMEO, University of Southern California.

Sandler, T. and Enders, W. (2004) An economic perspective on transnational terrorism. European Journal of Political Economy, 20, 301-16.

Siqueira, K. (2002) Conflict and third party intervention. MIMEO, Clarkson University, New York.

Sutton, J. (2001) Technology and Market Structure: Theory and Market History. The MIT Press.

Tavares, J. (2004) The open society assesses its enemies: shocks, disasters and terrorist attacks. Journal of Monetary Economics, 51, 1039-70.

Tessler, M. and Nachtwey, J. (1998) Islam and attitudes toward international conflict: evidence form survey research in the Arab world. The Journal of Conflict Resolution, 42, 5, 619-36.

Trajtenberg, M. (2003) Defense R\&D policy in the antiterrorist era. Discussion 
Paper No. 9725, National Bureau of Economic Research. 


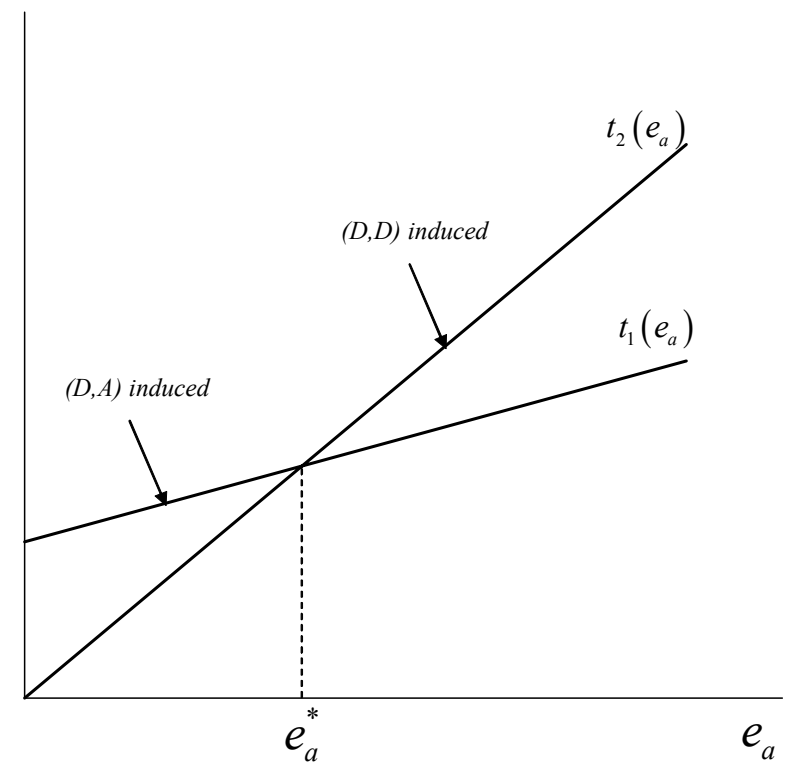

Figure 1: Small $\phi_{b}(D, A)-s_{b}$.

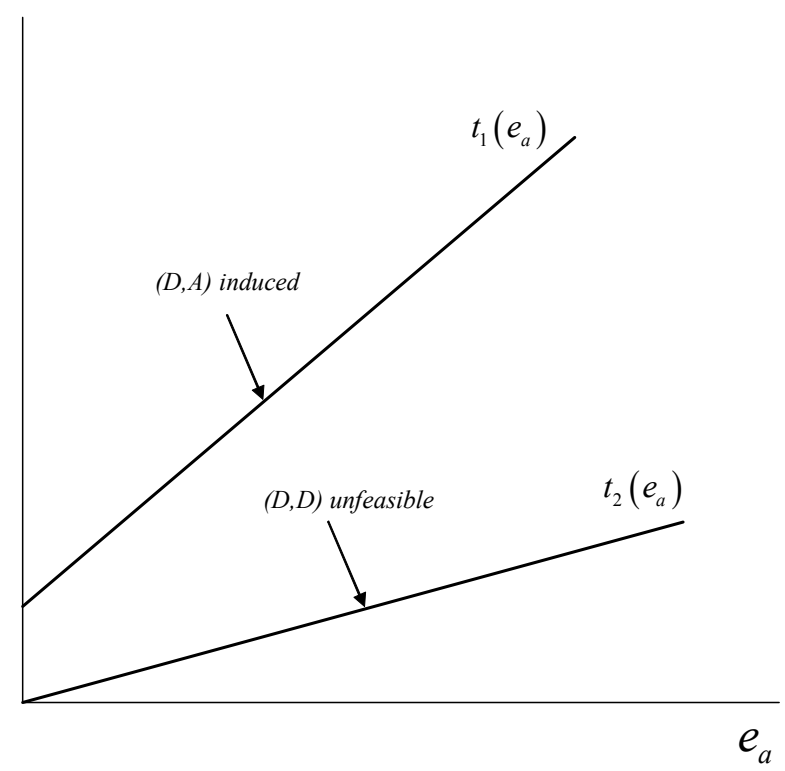

Figure 2: Large $\phi_{b}(D, A)-s_{b}$. 


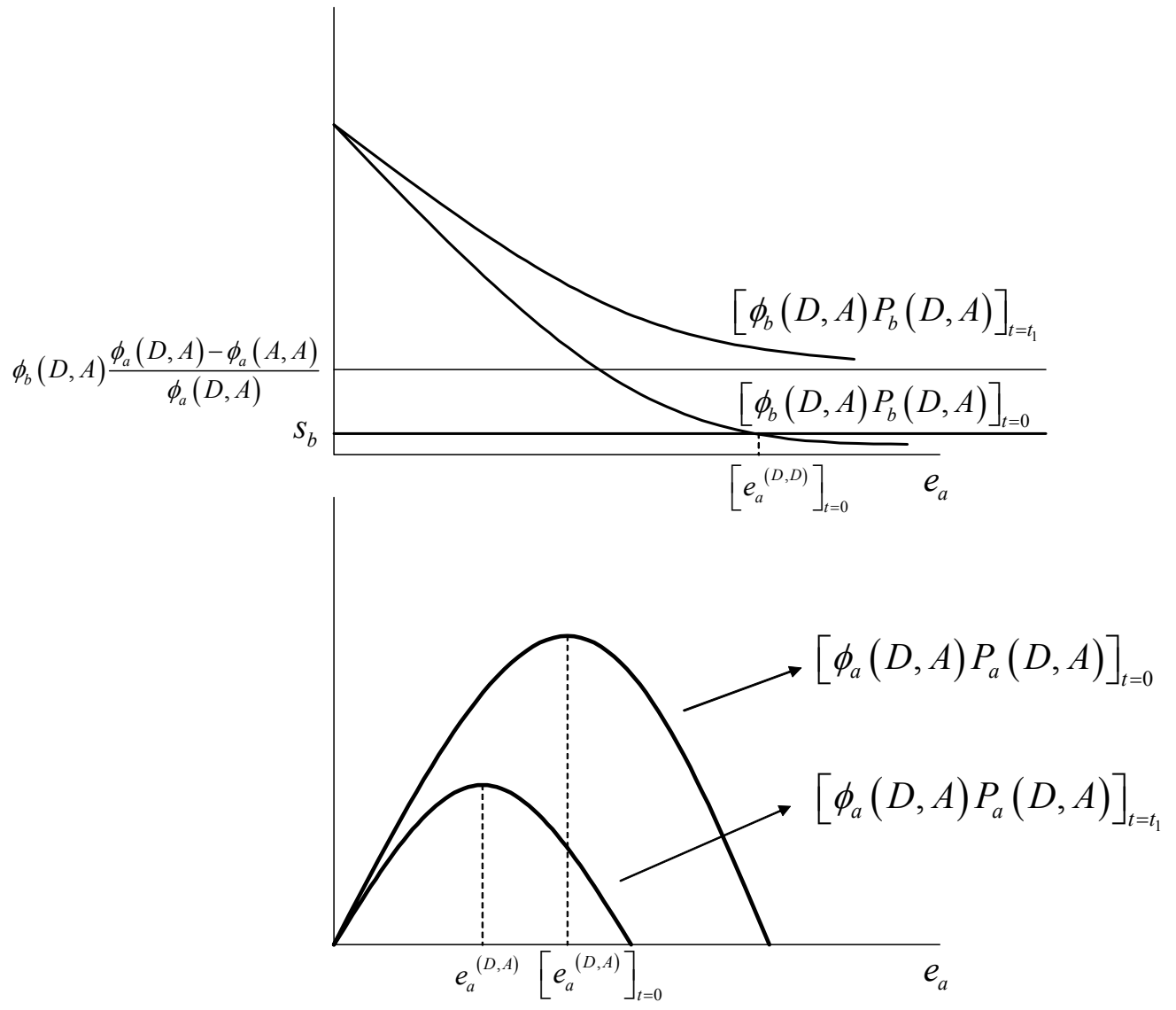

Figure 3: Example of peace becoming unfeasible with differentiation. 


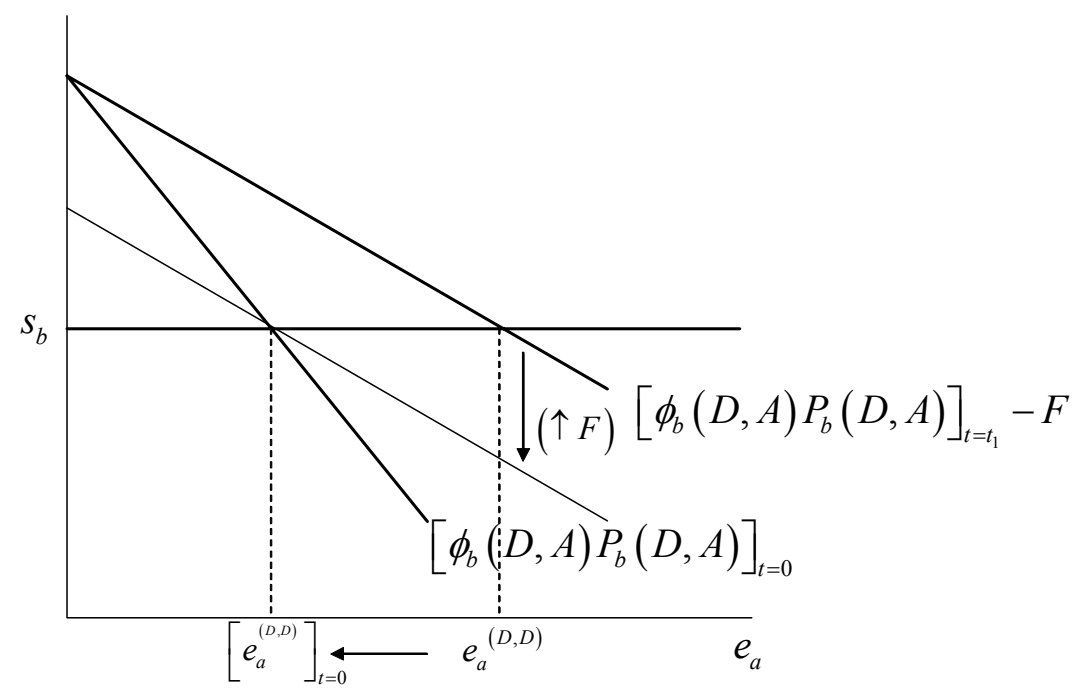

Figure 4: Impact on the conflict preventing level of effort of an increase in fixed costs of differentiation (from $F=0$ to $F=\widehat{F}$ ). 


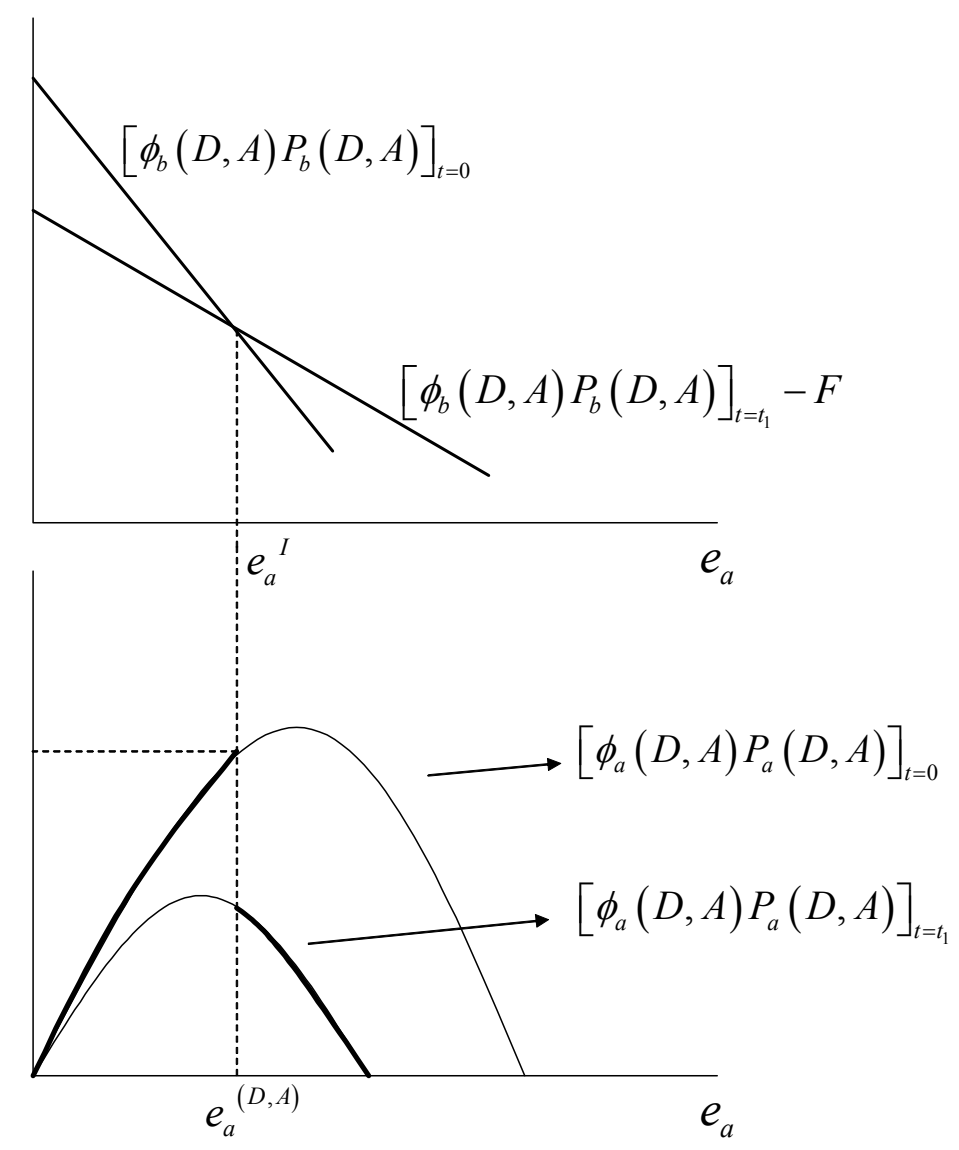

Figure 5: Thicker discontinuous curve represents the expected payoff for the incumbent for high $F$ if defensive conflict is expected. 


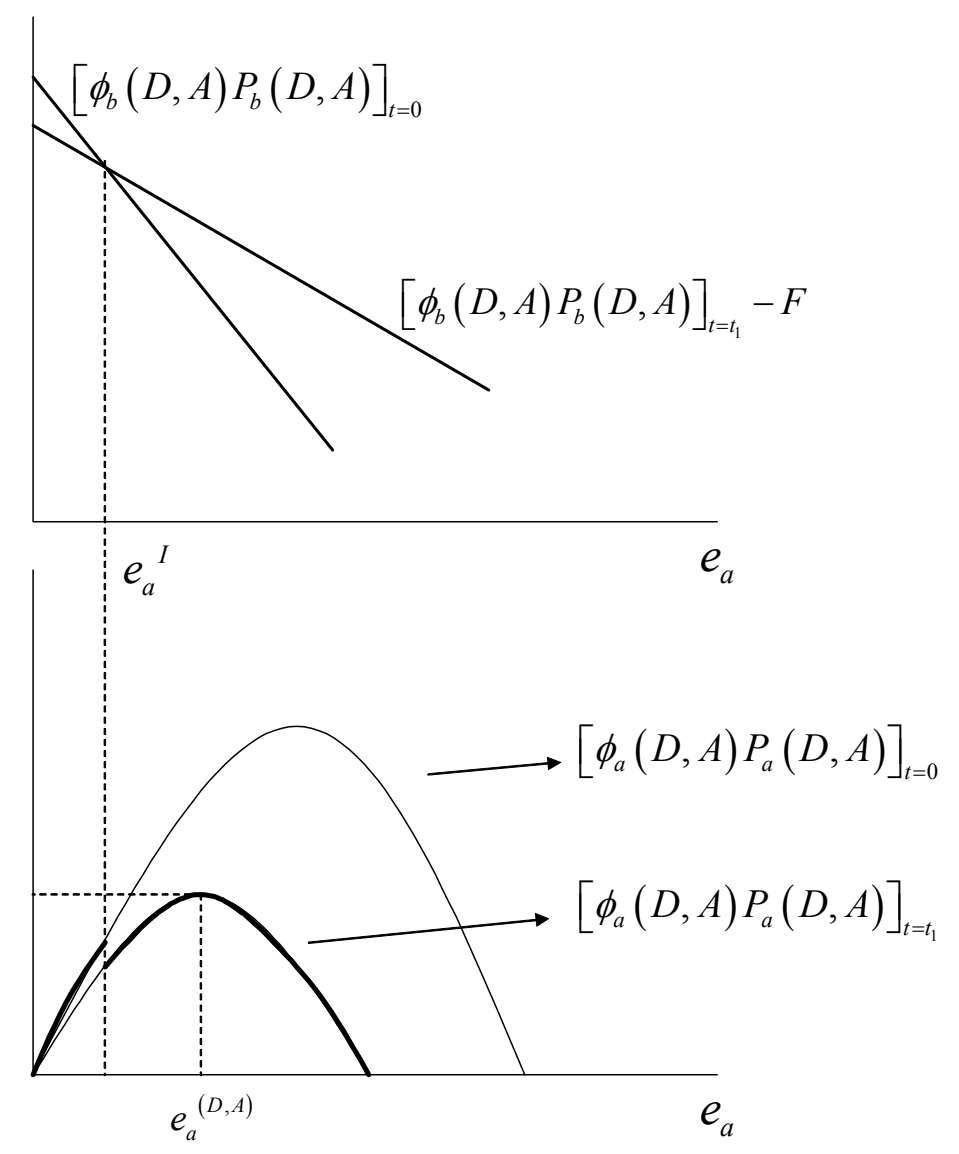

Figure 6: Thicker discontinuous curve represents the expected payoff for the incumbent for low $F$ if defensive conflict is expected. 


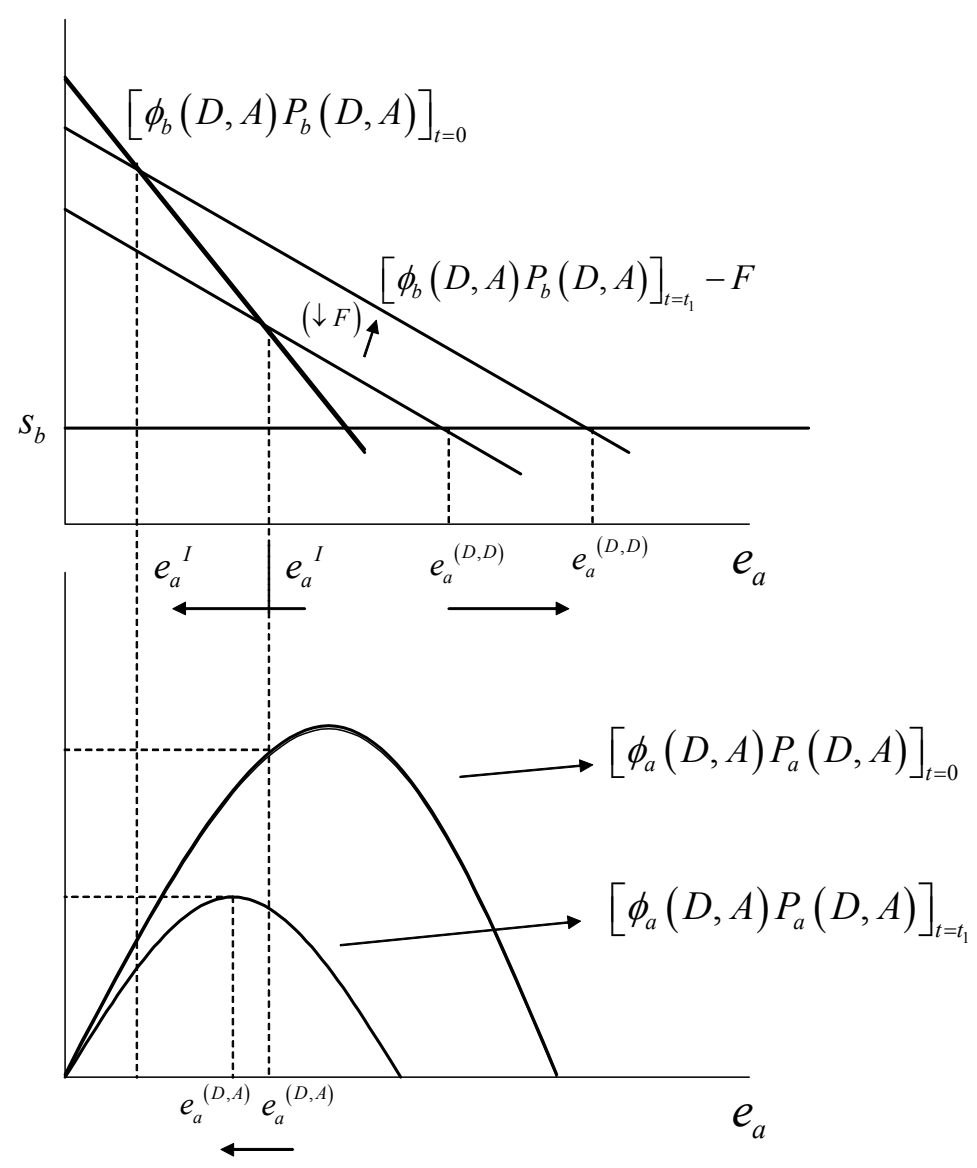

Figure 7: Impact on $e_{a}^{(D, A)}$ and $e_{a}^{(D, D)}$ of a decrease in $F$. 